\title{
Por un materialismo de la infancia. Una lectura de Las cosas de Arnaldo Antunes
}

\author{
ADRIANA CANSECO Universidad Nacional de Córdoba, Argentina / adrianacanseco@gmail.com
}

\begin{abstract}
Resumen
En el presente trabajo nos proponemos conjeturar la idea de un «materialismo de la infancia» en Las cosas de Arnaldo Antunes. Las características editoriales del libro permiten elaborar a partir de la relación entre imagen y escritura, un primer acercamiento al carácter «infantil» de Las cosas en el que será central el concepto de lengua apócrifa de Jean-Luc Nancy para delimitar su alcance e implicancias. La idea de infancia como umbral entre lenguaje y experiencia pondrá en juego a su vez el cuerpo como memoria táctil (Barthes) que trama el territorio material de la escritura. Este ejercicio de manipulación lúdica de la materia del lenguaje nos llevará a preguntarnos de qué manera la poesía juega en el límite que lleva la lengua hasta el extremo de sí misma.
\end{abstract}

Palabras clave: poesía / infancia / lengua apócrifa / cuerpo / experiencia

\section{For a materialism of infancy. A reading of Las cosas of Arnaldo Antunes \\ Abstract}

In this work we will think about a "materialism of infancy» in Las cosas of Arnarldo Antunes. The editorial characteristics of the book allow us to observe in the relationship between image and writing, the "infantile» characteristic of the book. The concept of the apocryphal language of Jean-Luc Nancy will be central to determine the implications of this sense of infancy. This concept of infancy as a limit between language and experience will put at stake the body as tactile memory (Barthes) that builds the material territory of writing. This exercise of language will make us wonder how poetry plays in the limit that take the language to the extreme of itself.

Key words: poetry / infancy / apocryphal language / body / experience

Recibido: 1/3/2020. Aceptado: 18/4/2020

Para citar este artículo: Canseco, A. (2020). Por un materialismo de la infancia. Una lectura de Las cosas de Arnaldo Antunes. El taco en la brea, 11 (diciembre-mayo), 112-122. Santa Fe, Argentina: UNL. DOI: 10.14409/tb.v1i11.9160 
As coisas têm peso, massa, volume, tamanho, tempo, forma, cor, posição, textura, duração, densidade, cheiro, valor. Consistência, profundidade, contorno, temperatura, função, aparência, preço, destino, idade, sentido. As coisas não têm paz.

Arnaldo Antunes

Cosa sosteniéndose sola como una piedra, una realidad opaca, una hoja, un clavo, una gota de tinta, una pasta o una pata.

Jean-Luc Nancy

\section{Materialidad de la escritura: escribir/dibujar las cosas}

El texto emblemático de la poesía de Arnaldo Antunes que tomamos como epígrafe, sin dudas más conocido por su versión musical' apareció publicado por primera vez en 1992 y le da título al conjunto del libro: As coisas [Iluminuras, São Paulo, 1992].

En Las cosas ${ }^{2}$ Antunes se interna, como en otros de sus libros, en el terreno de la poesía concreta, más específicamente plástico-visual, ligada en este caso a una concepción tipográfica del texto y de la imagen, a la que se suma un concepto particular de lenguaje que se desarrolla en el espacio ambiguo y libérrimo del juego. ${ }^{3}$ Este aparente juego convoca a una lengua familiar, suelta de ataduras retóricas, que podríamos identificar apresuradamente con un decir infantil. Sin embargo, esta rápida identificación exige precisiones: ¿por qué referirnos a la expresión poética de Las cosas con el término «infantil»?

En primer lugar, podemos conjeturar que este «decir infantil» se asocia al juego como transgresión del «buen sentido». Esta voluntad de juego se corresponde con un pensamiento que aparentemente desobedece los modelos de enunciación de la lengua canónica. En el caso particular de Las cosas, el libro está concebido como una suerte de pequeño diccionario o breviario ilustrado de términos (o nombres de "cosas») que aun atadas al lastre del significante devuelven una imagen renovada que revisita el sentido a veces absurdo que engendra la más estricta literalidad. El texto juega con el sentido obvio para señalar aquello que ya no resulta evidente a simple vista: su sentido material y la cadena de asociaciones ligada a esa materialidad.

Las cosas despliega un índice temático que bien podría formar parte del repertorio de cualquier enciclopedia para la primera infancia: el mar, los colores, el campo, las puertas, el cuerpo, la luz, los abuelos, los pechos, la mosca, los árboles, el puente, las gafas, el cielo, el tiempo, el fuego, el agua, la montaña, etc. Cada poema-entrada ofrece una definición categórica de inobjetable «buen sentido» y sin embargo el giro poético expone el lenguaje a su propio límite: «todas las cosas del mundo no caben en una idea. Mas todo cabe en una palabra, en esta palabra todo» (Antunes:25).

El poema del epígrafe, el más difundido y que le da título al libro, por ejemplo, repasa minuciosamente las propiedades físicas de la materia para poner a orbitar en el poema el sutil procedimiento de una lengua poética que apenas roza los ladrillos del razonamiento para desbaratar todo su edificio: «Las cosas tienen peso, masa, volumen, tamaño, tiempo, forma, color, posición, textura, duración, densidad, olor, valor. Consistencia, profundidad, contorno, temperatura, función, apariencia, precio, destino, edad, sentido. Las cosas no tienen paz» (Antunes:91). Como señala el poeta Héctor Bardanca en el texto de contratapa: «en una desprejuiciada y muy motivadora mirada desde el lado inocente del raciocinio (...) Las cosas logra ser forjado a partir de lo obvio para fijar una singularidad inquietante, que no pocas veces conlleva el plus de un sorprendente valor filosófico». 
La propuesta de Antunes en Las cosas es vulnerar los razonamientos arraigados a la estructura de la lengua y utilizarlos para validar «lo más nimio de lo cotidiano, lo más trillado y evidente del mundo» (Bardanca en Antunes).

La edición de Yaugurú reproduce fielmente el diseño gráfico y las imágenes de la original brasileña. Cada poema, diagramado tipográficamente de forma que el texto ocupe la totalidad de la página impar, está acompañado en la página par por un diseño de inequívoco trazo infantil. Cada doble página se constituye pues de una imagen sin título ni epígrafe, a veces indescifrable, y un texto que se acerca al humor a partir de la observación minuciosa de razonamientos formales, incluso solemnes.

Se trata de una serie de dibujos que Rosa Moreau Antunes, entonces de tres años de edad, fue trazando a pedido de su padre para la composición de este libro, escrito de tal manera a cuatro manos. Los dibujos, leídos paralelamente a los textos, funcionan en la unidad de la doble página, más que como ilustraciones, como otra forma de acceso a la cosa referida: cosa-palabra, cosa-imagen, cosa-idea, cosa-cosa.

Este aspecto resulta relevante si pensamos que la escritura y el dibujo quieren, en principio, acortar la misma distancia entre la significación y la cosa significada. Los elementales diseños de pulso infantil funcionan a su vez como poemas visuales: forma de escritura otra, primigenia, que no se revela aún en estructuras gramaticales pero que aspira a evocar la relación, el vínculo material que sostiene el lenguaje. Las cosas es también entonces, un objeto que exalta su pulpa orgánica, un ejercicio plástico visual donde padre e hija ensayan cada uno a su manera, abarcar el mundo en la doble página de un libro. En este sentido, las estructuras gramaticales que avalan un razonamiento objetivo tienen un valor equiparable al del dibujo infantil: ensayan una lectura del mundo, lo significan, lo cifran, lo ponen en riesgo-juego exponiendo su inabarcabilidad, su maravilla.

\section{La cosa, la lengua misma}

Ese decir de apariencia ingenua y literal de Las cosas, socava las bases del edificio racional que sostiene la relación entre mundo y lenguaje: ese decir poético puede refundar una cosmología urgente o transitoria de lo evidente que ensaya y pone en marcha, una y otra vez, una dialéctica propia: «El sol se va de noche y vuelve cuando la noche se va y se va cuando la noche vuelve y da la vuelta durante todo el día detrás de la noche de ayer» (Antunes:83).

Los poemas proceden de una observación objetiva (en el sentido de tangible e inmediata) y esforzadamente literal que como lectores asociamos a cierta verborrea irresponsable. Su «verdad», aunque irrebatible, resulta ajena a la precisión científica. Veamos por ejemplo, un ejercicio de taxonomía vegetal:

Los árboles son fáciles de hallar. Están plantados en el suelo. Maman el sol por las hojas y por la tierra beben agua. Cantan en el viento y reciben la lluvia de gajos abiertos. Están los que dan frutas y los que dan frutos. Los de copa ancha y los que habitan las ardillas. Los que llueven después de la lluvia, los cabelludos. (...) Crecen para arriba como las personas. Pero nunca se acuestan. El cielo aceptan. Crecen como las personas, pero no son sueltos en los pasos. Son más grandes, pero ocupan menos espacio. (Antunes:35)

Los poemas ajustan la mirada objetiva a la cosa misma del lenguaje: hacen signo, pero también espesura, volumen, forma, idea de la cosa. Con estas escenas-pa(i)sajes elementales Antunes teje 
una cosmología fáctica que observa los fenómenos a partir de una comprensión inicial del objeto de conocimiento y ensaya argumentos con voluntad científica:

El mar está siempre en movimiento para no salirse de lugar. Si el mar se saliese de lugar tendrían que cambiar los mapas. Si el mar se quedase parado se escurriría arriba de las ciudades y apagaría los volcanes. El agua sube cuando el sol la evapora. La sal del mar no se evapora. Cuando llueve sobre el mar el agua recupera la sal que había dejado allí con el resto de las aguas (...) Cuando el agua dulce del río llega ella deja de ser dulce porque el mar es más grande. Y cuando requiebra en la playa es bonito. Y hay gente que muere de sed en medio del mar. (Antunes:15)

o tantas otras apreciaciones sobre la naturaleza física de la materia:

El agua es agua cuando no se evapora ni se congela. El agua lava. El agua apaga el fuego. El hielo quema. El agua pasa entre los dedos. El río desemboca. El agua acaricia el canto rodado. El agua ahoga lo que no flota, hunde lo que no nada. (Antunes:65)

Pero, ¿cómo desarrolla su carnadura literaria esa experiencia de juego, de dónde proviene esta sugestión del lenguaje que bascula entre la seriedad casi solemne del enunciado enciclopédico y la burla pueril del absurdo? Hay en los poemas de Las cosas un simulacro de fidelidad en el que el lenguaje asume una voluntad de explicación imparcial que se vale del sentido evidente para atestiguar una cercanía de la cosa que permanecía olvidada. Pronto, esta búsqueda de objetividad revela su imposibilidad: imposibilidad de la equivalencia absoluta entre el significante material y la cosa; la irresoluble paradoja de tocar a la cosa con la cosa.

Que la lengua hace mundo más allá de sí misma, es lo que parece querer decir Las cosas: que la lengua se hace cosa en su búsqueda de la cosa, así como Rosa, de solo tres años ensaya sin intermediarios retóricos una lectura propia del mundo que la rodea.

En este sentido decimos que Las cosas está escrita a cuatro manos: hay tanto en la escritura como en el trazo infantil un mismo ritmo que se acompasa hasta fundirse, hasta dibujarseescribirse en la palabra del otro, poeta-niña. Allí hace la lengua poética su posibilidad, allí la cosa del lenguaje, los dibujos infantiles de Rosa Antunes y las cosas del mundo reivindican esa zona de juego en la que decir es hacer: y ese hacer poético supone la transgresión de la autoridad lingüística, moral, científica.

Sobre el derecho de decir-hacer soberano, Gilles Deleuze mismo se pregunta en su «Carta a un crítico severo»:

¿Por qué no tendría derecho a hablar de medicina sin ser médico si hablo de ella como un perro? ¿Por qué no podría hablar de la droga sin ser drogadicto si hablo de ella como un pájaro? ¿Por qué no podría inventar un discurso sobre cualquier cosa, incluso aunque se trate de un discurso completamente irreal o artificial, sin que se me tengan que reclamar los títulos que para ello me autorizan? (11)

Por qué no habría entonces derecho a hablar de todas las cosas del cosmos si se habla de ellas como un niño, es decir, entrando y saliendo del terreno del juego solemne de la razón, intentando a partir de la evidencia de lo dado, una lengua que juegue en el extremo de la trasparencia y en 
un delirio de realidad hasta tocar su reverso, allí donde defecciona, falla, cae en el absurdo y en la broma. Sin embargo, la lengua que se juega o arriesga hasta devenir apócrifa: «sin autenticidad, sin autoridad, sin autor atestado, sin reconocimiento de doctores, de leyes ni de asambleas» (Nancy, 2014:7), es la misma lengua del solemne diccionario, de la ley y de la autoridad.

Jean-Luc Nancy (2014) define a la poesía como la «manipulación obstinada de una lengua apócrifa» pero no se trata ni de «una hiperlengua, ni una metalengua, ni un idioma elucubrado» sino de la lengua misma. Todo lo atribuible a esa lengua apócrifa es también lo que caracteriza a la lengua canónica, porque aun «autentificada y depositada en gramáticas y diccionarios» (7) no deja de ser la misma lengua.

Lengua apócrifa: llena de prodigios y de sortilegios, de apocalipsis atronadores, de milagros y de visiones, de gnosis, de magias: pero todo lo que es revelado nunca es más que la lengua misma, y cómo ella revela que no hay nada que revelar, nada de ultralengua, sino que es la lengua misma, incansablemente su propia cesación su interrupción, y además el gesto y la cosa, el momento y el humor. (8)

La lengua apócrifa juega el doble juego de la ficción poética porque no pretende ser un puente para llegar al sentido (Nancy, 2013) sino lengua misma, puro objeto. Los poemas de Las cosas llevan al extremo esta apreciación: «el gesto y la cosa» son también imagen y texto, garabato infantil y lengua balbuceada, clausura de la imagen indescifrable y llamamiento de palabra-cosas, de ideas, despojos, retazos de palabras. «El momento y el humor», lo hecho del juego entre padre e hija y la risa que desarma las trampas de la literalidad: «lengua misma ella misma tendencialmente puro objeto, cosa depositada, bloque o polvo de palabras mineralizadas» (Nancy, 2014:9).

La «cosa» de Las cosas es en definitiva "la cosa del lenguaje», que está menos en la parodia de la dialéctica que en el juego literal cuya exposición descubre sus trampas, sus fronteras, sus atajos. Aquello que se revela como misterio en el poema, es en definitiva, la ausencia de misterio. Detrás de la palabra solo resta la palabra.

\section{La cosa y la infancia}

Los niños gustan de hacer preguntas sobre todo. No todas las respuestas caben en un adulto.

\section{Arnaldo Antunes}

Los dibujos realizados por la niña pequeña en el libro no son solo un original contrapunto estético-plástico del texto, mera representación o aspiración de objetualidad.

Si cuesta deslindar la anomalía del trazo infantil para descifrar en la imagen una representación de legible transparencia, por su parte la escritura también pone en juego un procedimiento de aparente simpleza creando un paralelismo que no fuerza la coincidencia sino que habilita múltiples accesos. La «cosa» del poema permanece en su singularidad: la imagen dice lo que dice y además otra cosa, y el texto se abre a ese encuentro habilitando significaciones, hasta desbordarse. Nancy se refiere a la lengua del poema en términos afines: 
del mundo. Porque la lengua al fin sirve para eso o para nada. Para excedernos infinitamente, a nosotros y a todos nuestros lenguajes. (2014:9)

Los poemas y dibujos se presentan como lenguaje excedido, escritura apócrifa de la manolengua-infantil que pone cuerpo en el nombre vaciado, de modo que aun en lo rudimentario del trazo-texto, hay lenguaje cifrado, poesía: «Lengua encriptada para revelar la cripta, la cifra, el escondite mismo: mostrar que no hay nada ahí, nada más que abertura de la boca donde la lengua se mueve» (Nancy, 2014:8-9).

Por medio de paisajes cifrados, textuales y gráficos, Antunes conduce a los lectores a donde la lengua se mienta, cada vez, desligada de las obligaciones del discurso dialéctico. Los textos y las imágenes de Las cosas, arraigados en la infancia (en la insensatez y el juego), más que parodiar risueñamente definiciones al modo canónico, abren la puerta al modo particular en que la poesía habilita espacios de inconmensurable posibilidad. Nancy también advierte esta potencia del poema que revela que, más allá del juego voluntario y novedoso, el arraigo infantil de esa lengua apócrifa determina el carácter poético que vemos emerger en Las cosas.

Terrenos vagos de la infancia donde se arrastran palabras inutilizadas, traficadas, inventadas, las medias palabras de quien habla apenas, balbucidas, farfulladas las necesidades de cancioncilla y de cantinela, mímicas de idioma, las compulsiones de citas y recitaciones, de encantamiento y de decantación. (2014:10)

Los poemas están hechos de intuiciones y de restos, de pequeñas observaciones recogidas aquí y allá, de certezas insignificantes descartadas por el discurso normalizado, purificado de puerilidades. Pero no solo eso, la poesía desanda la lengua hasta donde se pierden sus huellas, hasta que decanta: la búsqueda es siempre la de la palabra misma: no la adecuación entre palabra y cosa ni «nominación absoluta original» (Nancy, 2014:12), sino el regreso de la palabra misma a su identidad de cosa.

Acceder al sentido poéticamente no supone por tanto que la poesía sea, como señalábamos, un medio (mensaje) para alcanzar un fin (sentido). En «Hacer, la poesía» señala Nancy (2013) que la lengua poética no es un acceso al sentido sino un acceso de sentido. Este acceso es la negatividad de la poesía, aquello que la define: su dificultad (157). Pero la dificultad de Las cosas no se restringe al clásico atributo poético del sentido «elevado y conmovedor», sino que se constituye en la perplejidad y el asombro que razona los límites de lo posible. Más que la maravilla ante la existencia del mundo, el auténtico milagro es el lenguaje mismo: «Tanto las proposiciones cosmológicas, cuanto las proposiciones metalingüísticas, presuponen ya siempre que hay palabra. El verdadero milagro, en última instancia, surge cuando nos maravillamos por la existencia del lenguaje», señala Paolo Virno ${ }^{4}$ (38).

La lengua, en el límite de la significación se enfrenta a su propia potencia, haciéndose a sí misma, cada vez: «Poesía quiere decir: el primer hacer, o bien, el hacer en tanto que él es siempre primero, cada vez original». Si decir es hacer: «Poesía es hacer hablar todo y, a la vez, deponer todo hablar en las cosas» (Nancy, 2013:161-162).

Los poemas de Las cosas se hacen cosa, bibelot, juguete, artilugio, objeto de juego, máquina de risa, acceso de sentido que se derrama «en algunas palabras, sílabas, cadencias y frases de una lengua apócrifa» (Nancy, 2014:14). El hacer del poema es epicentro del milagro «como si el poema hiciera todo lo que puede ser hecho» (Nancy, 2013:160). 


\section{Hacer la lengua, soñar el cuerpo}

En la poesía, el cuerpo de la infancia deviene pequeño laboratorio de carne y sangre, de tacto y gusto, reservorio de una lengua futura como la que está latente en las imágenes que ensaya Rosa Antunes para acompañar los textos de su padre. En su ensayo 58 indicios sobre el cuerpo, Nancy advierte al modo en que Las cosas hilvana otros axiomas de la materia que:

El cuerpo es material. Es denso. Es impenetrable. Si se lo penetra, se lo disloca, se lo agujerea, se lo desgarra. (...) Es aparte. Distinto de otros cuerpos. Un cuerpo empieza y termina contra otro cuerpo. (...) Un cuerpo no está vacío. Está lleno de otros cuerpos, pedazos, órganos, piezas, tejidos, rótulas, anillos, tubos, palancas y fuelles. También está lleno de sí mismo: es todo lo que es. (2011:13)

Por su parte, la voz poética de Las cosas desliza como al descuido su propia hipótesis del cuerpo material:

El cuerpo existe y puede ser tocado. Es suficientemente opaco para que se lo pueda ver. Si te quedaras mirando años se puede ver crecer el cabello. El cuerpo existe porque fue hecho. Por eso tiene un agujero en el medio. El cuerpo existe, dado que exhala olor. Y en cada extremidad existe un dedo. El cuerpo si se corta expele un líquido rojo. El cuerpo tiene alguien como relleno. (Antunes:23)

Sin cuerpo no hay hacer posible; sin materia, no hay materialismo. La materia que conecta todos los puntos del tiempo son los cuerpos, la continuidad de todos los cuerpos y la pasión de su experiencia. Sin cuerpo no hay materialismo, ni experiencia, ni historia, ni lenguaje. El don del lenguaje es heredado en la infancia por vía materna. Es la lengua materna la que nos otorga, a cada uno, antes de la articulación, la materia del sentido. En el ensayo «La mater del materialismo histórico» León Rozitchner distingue la lengua materna de la lengua de la convención adquirida posteriormente:

nos damos cuenta que la lengua llamada paterna en la que todos estamos incluidos, que ordenó con su lógica nuestro pensamiento, en realidad supone necesariamente una «lengua» anterior que la lingüística ha dejado de lado. Y si tratamos de recuperar esa primera lengua, que no tenía palabras que permitieran la separación entre significante y significado, y era diferente por lo tanto a la que ahora hablamos, pero que iba creando sin embargo el lugar más propio de ese intercambio que nos abrió el sentido, y que es necesario suponerla para hablar luego la que ahora hablamos. (13)

Si recuperamos esa lengua, anterior a las convenciones canónicas, si recuperamos la primera lengua, la que habita aún, subterráneamente, el cuerpo mudo de la infancia, encontramos la poesía. El ensueño materno, - concepto central de Materialismo ensoñado- es por tanto, para Rozitchner (14), el éter (el afecto como sostén inasible en el que se inscribe la palabra) en el que el sentido circula. Pero el sentido no tiene una génesis espiritual sino profundamente material: para significar, la palabra arraiga «en un sentido encarnado en el cuerpo que se recorta y se despierta cuando las palabras lo tocan» (14).

Todo el fundamento materialista se justifica para Rozitchner en esta afección primaria del encuentro del cuerpo infantil con el cuerpo materno: «si la madre no hubiera abierto con el hijo 
el espacio del ensoñamiento que es la trama del pensamiento, ninguna lengua hubiera podido crearse, porque no habría habido una materia ensoñada en la cual inscribirse. No hubiera existido un materialismo histórico» (17).

La lengua se inscribe pues en la ensoñación materna y es posible porque proviene del afecto que funda la experiencia como memoria del cuerpo. Ensoñamiento es, por tanto: éter de la conciencia, trama sensitiva de la raíz de una lengua, lengua sustraída a los deberes de la Ley, lengua afectiva, balbuceada, susurrada, cantada, recitada, deformada por el juego, reída hasta la deformación del sentido.

En esta ensoñación como fundamento de la lengua materna se resguarda la materia que pone en acto lo que llamamos poesía, cuya verdad nos permite evocar la premisa de Nancy cuando señala que «toda lengua es apócrifa, auténticamente, y es quizá a fin de cuentas, todo lo que dice la poesía» (2014:7).

Si la poesía es el hacer por excelencia, «el primer hacer, cada vez original» (7), este hacer tiene lugar en la infancia. No la infancia transitoria sino la del inexorable umbral entre experiencia y lenguaje (Agamben). Entendida en tales términos, la infancia pone en juego, cada vez, el cuerpo. La conjunción lenguaje-cuerpo-infancia permite pensar otra lengua: ni autentificada, ni despótica, sin poder ni autoridad, ni reconocimiento ni ley; una que sea más bien la lengua del prodigio, del sortilegio, del milagro, de la visión, de la gnosis, de la magia, aquella que no guarda otro misterio que la lengua misma, el enigma revelado de la materia fónica y el trazo.

\section{Cuerpo-memoria}

En un breve ensayo, «La Lumière du Sud-Ouest» (Incidents), Roland Barthes señala un aspecto fundamental del origen de la escritura: las sugestiones estéticas y lingüísticas que dan forma a la escritura provienen en gran medida de la memoria del cuerpo de la infancia. No se trata de la memoria discursiva que organiza jerarquías temporales y dialécticas, sino la de la memoria sensitiva, involuntaria, que trama la materia misma de la escritura.

Previo a la dimensión histórica que lo inscribe en el tiempo del discurso, el cuerpo infantil se hace por con-tacto con el mundo circundante. El cuerpo es agente de la experiencia, opera un pasaje, un entre la materia de las cosas y la materia del lenguaje. Podemos leer en Barthes una hipótesis de esta experiencia del cuerpo como registro tangible del pasado, como memoria:

Entro en estas regiones de la realidad a mi manera, es decir con mi cuerpo; y mi cuerpo es mi infancia tal como la historia lo hizo (...) Así, a la edad en que la memoria se forma, sólo tomé de las "grandes realidades» la sensación que ellas me procuraban: olores, fatigas, sonidos de voces, recorridos, luces, todo lo que, de lo real, es de alguna forma irresponsable y no tiene otro sentido que el de formar más tarde el recuerdo del tiempo perdido. (18)

Barthes conjetura así el posible origen de una sensibilidad estética que se lleva inscripta en el cuerpo in-fante: experiencia no discursiva de sensaciones y ensoñaciones que forman parte de una lectura prediscursiva del mundo:

leer un país es primero percibirlo según el cuerpo y la memoria, según la memoria del cuerpo. Creo que es en este vestíbulo del saber y del análisis que es destinado el escritor: más consciente que competente, 
consciente incluso de los intersticios de la competencia. Es porque la infancia es la magnífica vía por la cual conocemos mejor un país. En el fondo, no hay más País que el de la infancia. (20)

Si bien, como señala Barthes, el de la infancia es el único país, también la infancia, es en sí misma, por derecho propio, un país: territorio inexpropiable del cuerpo habitado en la experiencia, estancia de la materia del lenguaje anterior al discurso, allí donde arraigan, antes aun de comprenderlos, los vínculos, los usos, la primigenia amalgama entre mundo y lenguaje. Sobre esta «experiencia histórica-arcaica» de la lengua materna Rozitchner ensaya una explicación de la manera en que esta es desplazada por el discurso dialéctico, cuya prepotencia no tarda en desconocer su fuente:

esa lengua que la madre vocaliza con el niño fue el fundamento de una experiencia sensible en la cual el sentido - atribuir una cualidad a una cosa - o la significación se formaban, pero que aún no habían alcanzado a construir los significantes sostenidos por la palabra de una lengua orgánica cuya estructura ex nihilo no se pregunta por la experiencia histórica-arcaica que la ha creado. (13)

Las posibilidades de conjeturar un materialismo de la infancia es más bien entonces una pregunta por la materia in-fante que teje el pasaje entre la «experiencia sensible» y el cuerpo que la padece y que se restituye al discurso como paisaje de signos deshilados, a partir de huellas, de marcas, de códigos que solo puede descifrar la piel que los ha encriptado en una anterioridad sin tiempo y sin lengua.

El materialismo de la infancia puede pensarse entonces como la posibilidad de la interrogación de ese «cuerpo» que como agente de la experiencia, determina filiaciones estéticas y lingüísticas, redes de impresiones pre-discursivas que sostienen las primeras «lecturas» del mundo a través de intensidades experienciales. En tal sentido, Rozitchner conjetura que «todo afecto entonces sería un condensado apretado, ceñido, de experiencias vividas pasadas, porque cuando lo sentimos y queremos decirlo aviva en sordina la epifanía primera que le sigue dando el matiz de su origen» (18).

Si bien también Barthes se refiere a una memoria sensorial (y para-discursiva) que permitiría una rememoración vívida del pasado, no se trata aquí de pensar en términos de nostalgia del tiempo perdido y del imposible retorno al país de la infancia sino en una temporalidad abolida de «la actualidad sin fin de lo finito» (Nancy, 2013).

En la propuesta de Antunes, la infancia no se conjuga en tensión con el pasado sino que, como materialidad, la infancia se juega en el pensamiento de una lengua apócrifa que se sostiene en el umbral del asombro, en el terreno donde se hace y se disputa la materia del cuerpo y la palabra vuelve a su fuente afectiva.

La latencia de la infancia (como umbral de la experiencia, epicentro del asombro, tiempoespacio de la epifanía, del milagro), se reafirma en el poema cuando pone en juego sus materiales: la materialidad de sus marcas, la impotencia del lenguaje y redistribuye los límites de lo circundante, dispone lo cercano y lo distante, lo evidente y lo aparente. Toma las estructuras del discurso dialéctico y lo plagia, juega con sus reglas:

Parecen rocas pero son nidos de termitas. Parecen frutos pero son colmenas. Parecen nubes pero son enjambres. Parecen lejos mas son pequeños. Parecen muertos mas están quietos. Parecen tierra mas están 
vivos. Parecen letras en los libros. Parecen inofensivos. Parecen grandes pero están cerca. Parecen lerdos pero están quietos. Parecen ser pero son inciertos. (Antunes:85)

Los enunciados de la suposición en el poema, se sostienen en la lógica de la adivinanza. La comparación hace surgir equivalencias entre el parecer con el padecer los insectos inciertos que no asoman en el nombre, sino como cosa entre las cosas, como apariencia entre apariciones. La simulación, la copia, el remedo, la falsificación de la lengua apócrifa hace aparecer el mundo bajo una luz más amable, más cercana a la impresión sensorial que guarda el cuerpo-memoria de la infancia.

El decir «ingenuo» de los poemas de Antunes pone en juego el saboreo detenido de los juegos de lenguaje, el borboteo de la lengua balbuceada, el puro sabor, la epifanía en el límite del asombro, en suma, la maravilla ante lo ilimitado de límite del mundo y del lenguaje que, cada vez, se expande y se reinventa. El milagro se da a través de la percepción de un límite insuperable (Virno:36): «Lejos de eludir los límites de la experiencia, el milagro surge precisamente de la experiencia del límite» (39).

La experiencia del lenguaje desbordado como asombro ante la inabarcabilidad de todo, puede ser analizado en términos del experimentum linguae que propone Agamben: «Lo inefable, lo inenarrable, son categorías que pertenecen únicamente al lenguaje humano: lejos de marcar un límite de lenguaje, expresan su invencible poder de presuposición». El sentido de aquello que se presenta como más allá del lenguaje «no es un inefable, sino lo máximamente decible, la cosa del lenguaje» (214).

El juego al que convoca Las cosas, parte del ensoñamiento que inaugura la historia y los discursos para quedarse allí donde el afecto le devuelve al lenguaje su sabor de epifanía. La necesidad de la poesía como materialismo de la infancia radica en devolver al cuerpo histórico el sentido que esa ensoñación materna le ha otorgado en el lenguaje. Sigilosamente, la lengua acomoda la infancia en el poema y reescribe la gracia del asombro, su límite sin fin.

El cielo. Está encima. El cielo está más arriba del suelo. De adentro del avión el cielo está alrededor, el cielo. Del piso no pasa. Más allá del campo gravitacional de la tierra pasa a ser el espacio. El cielo. Está desde el inicio del comienzo del principio. El cielo continúa. Encima del cielo hay más cielo. Y después de después del cielo del cielo ningún planeta, ningún cometa, ningún meteorito. Solo cielo y cielo y cielo sin fin ni infinito. (Antunes:53)

\section{Notas}

1 Esta canción fue grabada inicialmente para el disco Tropicalia 2 de Caetano Veloso y Gilberto Gil en 1993.

2 La edición en español de Las cosas que tomamos como referencia en este trabajo (traducción de Héctor Bardanca, Montevideo/ São Paulo: Yaugurú/ Grua Livros, 2012) reproduce fielmente el diseño tipográfico y la totalidad de las imágenes de la edición original brasileña (Iluminuras, 1992).
3 Arnaldo Antunes (n. São Paulo, 14 de septiembre de 1960) se define a sí mismo como un artista que no reconoce fronteras estrictas entre la poesía, la música, la performance, las artes visuales. En una entrevista de 2013 señala (https://www.lanacion. com.ar/1584561-arnaldo-antunes-soy-poeta-performer-musicotodo-eso): «Soy poeta, performer, músico, todo eso. No tengo una prioridad, ser una cosa más que otra. Trabajo en esto desde 
que era adolescente; empecé a tomar clases de guitarra con la intención de componer canciones; al mismo tiempo empecé a escribir los primeros poemas. Después, cuando di los primeros conciertos, se me despertó la cosa de usar el cuerpo como una información más junto a lo que estaba cantando. Mi poesía también desde muy joven fue performativa». La poesía de Antunes se mueve libremente entre la performance, la música y la poesía visual. Las cosas evoca un discurso soberano, que dice, o hace su decir de la materia misma de la lengua que ensaya una visión inaugural sobre el mundo. Lejos de mostrar simplemente una perspectiva asombrada y original, la voz poética discurre sobre la materia misma del mundo con un limitado puñado de materiales descartados del discurso adulto legitimado o pretenciosamente profesoral con igual convicción sobre su naturaleza.

Dentro de la variada y multifacética obra de Antunes, podemos considerar al libro que nos ocupa como un ejemplo de poesía concreta. El poeta Héctor Bardanca (2012), traductor del libro, señala en el texto de contratapa que: «Sin ser un texto de literatura infantil y aun habiendo sido aprobado por el Programa Nacional do Livro Didáctico del MEC de Brasil, esta obra rescata con frescura e inesperada perspectiva una actitud de niñez concentrada en lo lúdico, con la curiosidad y la picardía más espontánea, sin contracturas adultas y con despojada certidumbre, para acceder a jugar con la poesía en su múltiple realidad».

4 En este pasaje, Virno se refiere a la Conferencia sobre la ética de Wittgenstein, dictada originalmente en Cambridge en 1930 donde el autor vienés desarrolla el concepto de «asombro existencial» y que Paolo Virno traduce en el término «maravilla» [meraviglia] de la existencia del mundo como totalidad inabarcable en su ensayo La idea de mundo (Traducción de Ariel Penissi. La Marca, 2017.).

\section{Referencias bibliográficas}

Agamben, G. (2004). Infancia e historia. Ensayo sobre la destrucción de la experiencia. Buenos Aires: Adriana Hidalgo. Traducción de Silvio Mattoni.

Antunes, A. (2012). Las cosas. Montevideo/São Paulo: Yaugurú/Grua Livros. Traducción de Héctor Bardanca.

Barthes, R. (1997). Incidents. Paris: Editions du Seuil. Traducción propia.

Deleuze, G. (1996). Conversaciones 1972-1990. Valencia: Pre-Textos. Traducción de José Luis Pardo.

Nancy, J-L. (2011). 58 indicios sobre el cuerpo. Extensión del alma. Buenos Aires: La Cebra. Traducción de Daniel Alvaro.

(2013). Hacer, la poesía. Badebec. Revista del Centro de Estudios de Teoría y Crítica Literaria, 3(5),

155-163. Traducción de Gabriela Milone. https://revista.badebec.org/index.php/badebec/article/view/6o (2014). Lengua apócrifa. Santiago de Chile: Cuadro de Tiza. Traducción de Juan Soros.

Rozitchner, L. (2011). Materialismo ensoñado. Buenos Aires: Tinta Limón.

Virno, P. (2017). La idea de mundo. Intelecto público y uso de la vida. Buenos Aires: La Marca. Traducción de Ariel Pennisi. 